15. Современные образовательные технологии: учебное пособие / кол. авт., под ред. Н.В. Бордовской. М.: КНОРУС, 2011. 432 с.

16. Антонов Г.М. Исследование эффективности системы компетентностной профессиональной подготовки офицеров запаса автомобильных войск // Известия Самарского научного центра Российской академии наук. Социальные, гуманитарные, медикобиологические науки. 2013. Т. 15, № 2-4. С. 865-869.

17. Кальней В.А., Матвеева С.В. Проблема комплексной оценки качества профессиональной подготовки студентов в условиях компетентностного подхода // Вестник РМАТ. 2011, № 3 (3). С. 120-124.

18. Дульзон А.А., Васильева О.М. Система самооценки и оценки компетенций научно-педагоги- ческих кадров // Высшее образование в России. 2014. № 5 (14). С. 61-72.

19. Антонов Г.М., Афанасьев А.К. Использование компетентностно-модульной технологии подготовки офицеров запаса на военных кафедрах гражданских вузов // Современные проблемы подготовки специалистов атомной отрасли: материалы всерос. науч.практ. конф. Димитровград: Димитровградский инженерно-технологический институт, 2015. С. 20-25.

20. Михелькевич В.Н., Овчинникова Л.П. Учебный модуль-конструкт самоуправляемой дидактической системы формирования предметных компетенций // Вестник Самарского государственного технического университета. Серия «Психолого-педагогические науки». 2011. № 1 (15). С. 83-88.

\title{
PEDAGOGICAL SYSTEM OF MILITARY-PROFESSIONAL COMPETENCIES DEVELOPMENT OF PROSPECTIVE RESERVE OFFICERS OF THE RUSSIAN FEDERATION ARMED FORCES
} (C) 2018

Antonov Gennady Mikhailovich, candidate of pedagogical sciences, lecturer of Military Department Afanasev Andrey Konstantinovich, candidate of pedagogical sciences, professor of Military Department Mikhilkevich Valentin Nikolaevich, doctor of technical sciences, professor of Psychology and Pedagogy Department Samara State Technical University (Samara, Russian Federation)

Abstract. The paper presents theoretical and methodological foundations for the construction and practical implementation of the pedagogical system of military-professional competencies development of prospective reserve officers of the RF armed forces. The authors justify the urgency of social and economic expediency and specificity of the reserved for the Armed Forces officers' training in civil technical universities. The authors give theoretical and experimentally confirmed justification of content and structure of military-professional competence of the reserved future officer. The authors have generalized an algorithmic model of pedagogical system of students' (prospective reserve officers of the military-professionals) competence development. Its structure contains ten functional, interrelated and consistently implemented blocks. The authors describe a functional purpose and essential content of each block of the system model. Special attention is given to the modular technology of military-professional competence development, principles of organization, methods and techniques of its implementation. The authors provide data of a pedagogical experiment that identifies students' level of military-professional competence development in the experimental and control groups at the levels of their cognitive, operational and activity components development.

Keywords: technical institute students; reserve officers; military-professional competencies; pedagogical system; pedagogical system model; modular technology of education; evaluation criteria; evaluation tools.

\section{ФОРМИРОВАНИЕ ГОТОВНОСТИ БУДУЩИХ УЧИТЕЛЕЙ К ПРИОБЩЕНИЮ ШКОЛЬНИКОВ К ЦЕННОСТЯМ ФИЗИЧЕСКОЙ КУЛЬТУРЫ В ПРОЦЕССЕ ИЗУЧЕНИЯ УЧЕБНОЙ ДИСЦИПЛИНЫ «ПЕДАГОГИКА»}

(C) 2018

Борисов Александр Яковлевич, кандидат педагогических наук, заведующий кафедрой физического воспитания

Самарский государственный социально-педагогический университет (2. Самара, Российская Федераџия)

Аннотациия. В статье актуальность решения задачи формирования готовности студентов - будущих учителей к приобщению школьников к ценностям физической культуры обосновывается в контексте проблемы сохранения человека как социального существа и как биологического вида. Ценности физической культуры рассматриваются как предпосылка достижения гармоничного сочетания в человеке телесного и духовного начал, как условие полноценного бытия школьника, студента. Выделяются конкретные ценности физической культуры: «двигательная активность человека», «жизнь человека», «здоровье», «здоровый образ жизни», «культура», «настойчивость в достижении цели», «нравственное совершенство», «самореализация» и др. Приводится структура готовности будущего учителя к приобщению школьников к ценностям физической культуры, включающая когнитивный мотивационно-ценностный и деятельностный компоненты. Раскрываются возможности учебной дисциплины «Педагогика» в формировании готовности будущих учителей к приобщению учащихся к ценностям физической культуры в теоретическом и практическом аспектах. Теоретический аспект: выделение на уровне научного материала разделов учебной дисциплины «Педагогика» ценностей физической культуры (раздел «Введение в педагогическую деятельность»- ценности «жизнь человека», «культура», «настойчивость в достижении цели», «самоопределение», «самоорганизация» и др.; 
раздел «Решение профессиональных задач» - ценности «здоровье», «здоровый образ жизни», «настойчивость в достижении цели», «престиж занятий физической культурой и спортом» «свобода», «справедливость» и др.). Практический аспект: конкретные примеры формирования готовности будущих учителей к приобщению школьников к ценностям физической культуры на лекционных и семинарских занятиях по разделам «Решение профессиональных задач» и «История педагогической мысли в России и за рубежом». Делается вывод о том, что освоенные студентами ценности станут ориентирами по воспитанию школьника, ответственно относящегося к собственному здоровью и здоровью окружающих людей.

Ключевые слова: готовность; студент; будущий учитель; физическая культура; ценность; ценность физической культуры; учебная дисциплина; педагогика; здоровье; здоровый образ жизни; педагогическая задача; решение; рефлексия; ориентация; приобщение; школьник; формирование; процесс.

Современному этапу развития человеческой цивилизации присущи многообразные глобальные проблемы, среди которых особое место занимает проблема сохранения человека и как социального существа, и как биологического вида. Важность данной проблемы объясняется не только наличием экологических рисков, но и отношением самого человека к себе, к своему здоровью. Особое место здесь занимает здоровье детей. Так, результаты обследования московских школьников с 2005 по 2015 годы, проведенного НИИ гигиены и охраны здоровья детей и подростков ФГАУ «Национальный научно-практический центр здоровья детей» Минздрава РФ, показывают, что среди российских старшеклассников нет полностью здоровых людей: «В ходе исследования всех детей разделили на четыре группы по состоянию здоровья. В I группу попали абсолютно здоровые дети, во II - те, кого можно считать "практически здоровым", а в III и IV оказались те, кто страдает острыми и хроническими заболеваниями. Среди первоклассников к I и II группам относились 4,3\% и 44\% школьников. Среди 11-классников абсолютно здоровых детей уже не осталось. Доля "практически здоровых" снизилась до 34\%. У каждого второго выпускника диагностированы хронические заболевания. Самые распространенные отклонения: нарушения сердечно-сосудистой и костно-мышечной систем, органов дыхания, нервной системы и психической сферы, а также расстройства зрения. Наиболее часто встречающиеся хронические заболевания: язвенная болезнь, гастродуоденит, сколиоз, близорукость средней и высокой степени» [1].

Решение задачи ориентации школьников на сохранение и укрепление здоровья во многом зависит от учителя. Способом такой ориентации является приобщение учащихся к ценностям физической культуры, оптимальное соотношение которых, по утверждению С.С. Коровина и Л.Н. Малорошвило, является реальной предпосылкой «достижения личностно и социально востребуемого соотношения в личности ее надбиологических телесно-душевнодуховных начал, качеств и свойств как отражения сформированности социокультурной личности (как главного «продукта» образования)» [2, с. 288].

М.Я. Виленский пишет: «Ценности физической культуры обогащают, направляют и творят бытие студента в его телесных проявлениях (здоровье, телосложение, осанка, техничность движений, выносливость и др.). Они развивают как субъектнообъектные отношения студента в физической культуре (к своей самости), так и межсубъектные (к другим людям), позволяют студенту раскрыть свою телесную сущность и одновременно являются условием его полноценного бытия» [3, с. 63]. Мы полагаем, что данное высказывание ученого относительно ценностей физической культуры в полной мере может быть отнесено и к школьникам.

Анализ научной литературы по проблеме ценностей в физической культуре [2-13] позволил выделить в качестве таких ценностей следующие: «двигательная активность человека», «жизнь человека», «здоровье», «здоровый образ жизни», «знание», «культура», «настойчивость в достижении цели», «нравственное совершенство», «престиж занятий физической культурой и спортом», «самоопределение», «самоорганизация», «самореализация», «свобода», «справедливость», «творчество», «тело человека», «трудолюбие», «физическое совершенство».

Для того чтобы приобщение школьников к данным ценностям было эффективным, необходимо, чтобы, во-первых, они стали достоянием смысловой сферы сознания учителя, работающего с учащимися; во-вторых, чтобы педагог обладал готовностью к приобщению школьников к ценностям физической культуры. Формирование такой готовности будущего учителя в период его обучения в педагогическом вузе является одной из актуальных задач, стоящих перед современным российским педагогическим образованием, так как позволяет подготовить педагога, не только освоившего систему ценностей физической культуры для себя и реализующего ее в своей жизнедеятельности, сохраняющего и укрепляющего собственное здоровье, но и ориентированного на приобщение школьников к данным ценностям. Становясь достоянием смысловой сферы сознания учащихся, ценности физической культуры ориентируют их на здоровый образ жизни, тем самым способствуя сохранению человека как биосоциальной структуры.

Обоснованная нами структура готовности будущего учителя к приобщению школьников к ценностям физической культуры включает когнитивный мотивационно-ценностный и деятельностный компоненты, содержание которых образуют знания (о культуре, о физической культуре и ее ценностях и др.), ценности («жизнь человека», «здоровье», «знание», «культура», «нравственное совершенство» и др.), умения (умение ориентировать школьников на нравственное и физическое совершенствование, умение ориентировать учащихся на здоровый образ жизни, умение создавать благоприятный психологический климат в учебно-воспитательном процессе и др.) $[14$, с. 11-23].

В рамках данной статьи мы покажем возможности учебной дисциплины «Педагогика» в формировании данных компонентов готовности.

Учебная дисциплина «Педагогика» изучается будущими учителями на протяжении первых трех курсов. Рассматриваемая учебная дисциплина включает 
такие разделы, как «Введение в педагогическую деятельность», «История педагогической мысли в России и за рубежом», «Основы педагогики и нормативно-правовое обеспечение образования», «Теория и технология обучения», «Теория и технология воспитания» «Решение профессиональных задач». Как показал наш опыт работы, все разделы позволяют формировать готовность студентов - будущих учителей к приобщению школьников к ценностям физической культуры.

Анализ содержания учебной дисциплины «Педагогика» позволил выделить на уровне научного материала ее разделов ценности физической культуры. Например, на уровне раздела «Введение в педагогическую деятельность» можно выделить такие ценности, как «жизнь человека», «культура», «настойчивость в достижении цели», «самоопределение», «самоорганизация», «самореализация», «творчество», «тело человека»; на уровне раздела «Основы педагогики и нормативно-правовое обеспечение образования» - «двигательная активность человека», «здоровье», «здоровый образ жизни», «знание», «нравственное совершенство», «трудолюбие», «физическое совершенство»; на уровне раздела «Решение профессиональных задач» - «здоровье», «здоровый образ жизни», «настойчивость в достижении цели», «престиж занятий физической культурой и спортом» «свобода», «справедливость» и т.д.

Обратимся к конкретным примерам и покажем формирование готовности будущих учителей к приобщению школьников к ценностям физической культуры на занятиях по педагогике.

Раздел «Решение профессиональных задач».

Лекция на тему «Здоровьесберегающие технологии в образовательном процессе». Студенты знакомятся с сущностью и содержанием понятия «здоровьесберегающая образовательная технология», рассматривая здоровьесбережение как качественную характеристику любой образовательной технологии, являющуюся своеобразным сертификатом безопасности конкретной технологии. Преподаватель раскрывает перед будущими учителями здоровьесберегающую образовательную технологию как совокупность приемов, методов, форм педагогической деятельности, дополняющих традиционные технологии воспитания и обучения профессиональными задачами здоровьесбережения.

Студенты знакомятся с основными признаками, которым отвечает здоровьесберегающая образовательная технология: «1) системность, гармонизирующая цель и содержание образовательного процесса, ориентированного на воспитание здоровья учащихся; 2) научность, позволяющая концептуально оформить цель; 3) гарантированность результата, достигаемого с помощью диагностически сформированной цели, получения информации о состоянии здоровья учащихся, системы контроля, адекватной цели воспитания здоровья (обратные связи)» [15, с. 25].

Преподаватель разъясняет будущим учителям сущность принципов реализации здоровьесберегающей образовательной технологии, предложенных Н.К. Смирновым [16, с. 26-34]. Так, принципы не нанесения вреда и приоритета действенной заботы о здоровье школьников означают, что процесс получения учащимся знаний, развития умений и навыков ни в коем случае не должен разрушать его здоровья (например, чрезмерное количество заданий, когда у ребенка не остается времени на физическую активность). Принцип триединого представления о здоровье требует, чтобы образовательный процесс был равным образом направлен на сохранение и укрепление физического, психического и духовнонравственного здоровья учащегося. Принцип субъект-субъектного взаимоотношения с учащимися позволяет воспитывать школьников как субъектов собственного здоровьесбережения. Помимо указанных преподаватель ведет речь о принципах приоритета позитивных воздействий (подкреплений) над негативными (запретами, порицаниями), приоритета активных методов обучения; о принципе сочетания охранительной и тренирующей стратегий; принципе непрерывности и преемственности; принципе соответствия содержания и организации обучения возрастным особенностям учащихся; принципе комплексного междисциплинарного подхода; принципе гармоничного сочетания обучающих, воспитывающих и развивающих педагогических воздействий; принципе формирования ответственности учащихся за свое здоровье; принципе отсроченного результата; принципе контроля за результатами.

Раскрывая сущность обозначенных принципов, преподаватель основное внимание уделяет их реализации в контексте успешного использования учителем в своей профессиональной деятельности умений, которые образуют содержания деятельностного компонента готовности. Так, принцип триединого представления о здоровье (единство физического, психического и духовно-нравственного здоровья) позволяет эффективно реализовывать умение ориентировать учащихся на нравственное и физическое совершенствование; принцип приоритета действенной заботы о здоровье учащихся - умения ориентировать учащихся на здоровый образ жизни и т.д.

Лекция на тему «Педагогическая задача и технология ее решения». Преподаватель раскрывает понятие «педагогическая задача» и знакомит будущих учителей с видами педагогических задач, а затем показывает соотношение понятий «педагогическая технология» и «педагогическая задача» в контексте проблемы приобщения учащихся к ценностям физической культуры.

На семинарском занятии по обозначенной теме студенты овладевают технологией принятия педагогических решений. Такое овладение происходит в процессе знакомства будущих учителей с обоснованным Ю.Н. Кулюткиным механизмом движения педагогического знания. Суть данного механизма заключается в следующем: вначале у учителя формируется ведущая идеи, задающая общую направленность его деятельности; затем данная идея, отражая опыт педагога в его противоречивости и развитии, начинает выполнять в практическом мышлении учителя функцию конструктивного принципа действия и функцию критерия анализа и оценки ситуации; далее осуществляется конкретизация идеи в конкретную схему (модель, проект) решения задачи, и, наконец, создается конструктивная схема - регулятор деятельности педагога по решению конкретной педагогической задачи [17, с. 47-53]. 
Затем преподаватель показывает будущим учителям, как в ситуации принятия педагогического решения реализуются конкретные умения, образующие содержание деятельностного компонента готовности учителя к приобщению учащихся к ценностям физической культуры. Результативный поиск педагогического решения, предполагающий реализацию вышеназванных умений, требует от студента рефлексивных способностей. Иными словами, создавая конструктивную схему как регулятор деятельности на основе ведущей идеи, создавая программу деятельности педагога по практическому воплощению идеи в педагогическую действительность, необходимо, говоря словами М.Б. Туровского, «объединить отобранные способы возвращенными определениями целостности цели. Успешность этой работы прямо зависит от развития рефлексивной способности индивида» [18, с. 191].

На описываемом, а также на других семинарских занятиях в рамках раздела «Решение профессиональных задач» происходит развитие у студентов способности к педагогической рефлексии.

Покажем примеры педагогических задач, с помощью которых развивается способность будущих учителей к педагогической рефлексии.

Задача: Престижная гимназия. Седьмой класс. Учащиеся дружные. В классе царит дух товарищества и взаимопомощи. В такой класс пришел работать новый классный руководитель. Вначале класс ему понравился, но вскоре выяснилось одно «но»... Класс охотно участвует во внеклассной работе. Особенно в интеллектуальных конкурсах. По большинству предметов в классе высокая успеваемость. Однако наблюдается пренебрежительное отношение к физической культуре. Семиклассники уверены, как показали беседы с ними, что главное - получать знания по серьезным предметам: по языкам, математике, физике и т.д., так как эти знания помогут получить престижное высшее образование, устроиться в жизни. Физическая культура, по мнению подростков, отнимает время, которое они могли бы посвятить изучению других предметов либо отдыху. Пренебрежительное отношение к предмету распространяется и на учителя физической культуры. Семиклассники не реагируют на его замечания, придумывают различные причины для пропуска уроков, в то время как любое требование учителей математики, физики выполняются неукоснительно.

Bonpocbl: «С чем, по вашему мнению, связана сложившаяся в классе ситуация?», «Что может в данной ситуации сделать классный руководитель?», «Предложите конкретные пути повышения престижа занятий физической культурой и спортом в данном классе».

Работе с содержанием педагогической задачи предшествует ознакомление студентов с предлагаемыми Ю.Н. Кулюткиным этапами решения педагогической задачи: проектирование, реализация, оценка, пронизанные аналитическими и конструктивными процессами [19, с. 16].

Направляемые преподавателем, будущие учителя определяют ведущую идею задачи. Такая задача формулируется студентами как «воспитание здоровья». Опыт показывает, что студенты, как правило, полагают, что ведущей идеей является идея повыше- ния престижа занятий физической культурой и спортом. Однако в процессе размышлений будущие учителя осознают, что повышение престижа занятий физической культурой и спортом является лишь одним из средств воспитания здоровья учащихся, их ориентации на здоровый образ жизни.

Осуществляя ориентацию в рассматриваемой ситуации, будущие учителя, выявив отношение школьников к физической культуре, формулируют педагогическую задачу, а затем предлагают способы ее решения. Это может быть беседа со школьниками и их родителями, организация спортивных соревнований и другие способы.

Задача: В девятый класс пришел новый ученик. Подросток хорошо учится, эрудирован, всегда готов помочь с домашним заданием, общителен. Сергей не жадный. Он охотно делится с одноклассниками своим большим собранием компьютерных игр, книгами. Подросток серьезно увлекается компьютерами и является победителем престижных турниров по компьютерным играм. Все это вместе взятое делает его интересным для товарищей, с ним хотят дружить. Сергей очень нравится одноклассникам. Но при всех этих положительных качествах, у подростка есть серьезный недостаток. Сергей почти уже целый год курит. Родителя подростка не только об этом знают, но и спокойно к этому относятся. Причем родители работают на руководящих должностях, занимая довольно высокое положение. Они сами давно курят и полагают, что главное, чтобы сын их не обманывал, - если хочет курить, пусть курит у них на глазах, а не в подворотне с сомнительной компанией. Именно так высказался отец, когда классный руководитель вызвал его в школу по поводу курения сына. Подражая Сергею, многие его одноклассники потянулись к сигаретам.

Задание: «Что должен сделать классный руководитель для преодоления этой вредной привычки у девятиклассников? Предложите систему действий».

Проанализировав ситуацию и сформулировав задачу, студенты предлагают в качестве способа ее решения организовать беседу с девятиклассниками врача. Суть такого решения заключается в обращении в процессе беседы со школьниками к их сознанию, апеллирование к смысловой сфере сознания.

Руководя решением данной педагогической задачи, преподаватель стремится, чтобы будущие учителя поясняли, какие умения педагога должны быть реализованы на каждом из этапов ее решения. Студенты определяют ведущую идею задачи, разрабатывают проект решения, конструктивную схему, регулирующую деятельность учителя.

Раздел «История педагогической мысли в России и за рубежом». Тема «Генезис научных представлений о здоровьесбережении детей». В рамках данной темы рассматриваются различные модели формирования здорового образа жизни школьников, воспитания у них здоровья. В частности, будущим учителям для осмысления предлагаются модели воспитания здоровья, обоснованные Э. Чарлтоном: медицинская (профилактическая) модель; образовательная модель; радикально-политическая модель; модель самоусиления [20, с. 3-13].

На семинарском занятии по данной теме будущие учителя находят различия между этими моделями. 
Так студенты приходят к мысли, что различия между данными моделями заключаются в объекте, на который они направлены. Образовательная модель направлена на индивида, радикально-политическая апеллирует к социуму. Объект медицинской модели - информация. Медицинская, или, как ее еще называют, профилактическая, модель является чисто когнитивной. В рамках данной модели учащиеся информируются о вреде или пользе для здоровья различных факторов и явлений. В контексте решения проблемы подготовки учителя, обладающего готовностью к приобщению учащихся к ценностям физической культуры, актуальной представляется образовательная модель. На семинарском занятии студенты уясняют содержание и последовательность этапов осуществления педагогом выбора действий при реализации данной модели: «1. Всестороннее рассмотрение широкого спектра альтернативного поведения. 2. Рассмотрение всех целей, которые должны быть достигнуты, и оценка ценностей, связанных с совершаемым выбором. 3. Тщательное взвешивание того, все ли отрицательные последствия наряду с положительными известны применительно к каждому образу действий. 4. Активный поиск информации важный для оценки альтернатив. 5. Объективная оценка поступающей информации и полученных мнений экспертов, даже если они идут в разрез с тем образом действий, к которому изначально склонялся индивид. 6. Повторная оценка положительных и отрицательных последствий всех известных альтернатив, даже тех, которые изначально рассматривались как неприемлемые, прежде чем будет принято окончательное решение. 7. Составление детального плана осуществления избранного курса, учет возможности его изменений в случае реализации нежелательных последствий» [20, с. 5].

На семинарском занятии студенты обсуждают разработанные Э. Чарлтоном рекомендации, следование которым позволит реализовать образовательную модель воспитания здоровья и формирования здорового образа жизни $[20$, с. 5-6], и конкретизируют их в контексте будущей педагогической деятельности по приобщению учащихся к ценностям физической культуры: во-первых, необходимо оценить проблему (например, проблема курения школьников) и на основе оценки определить способы решения проблемы (беседа с врачом, порицание, вызов родителей в школу, запрет и т.д.). При этом необходимо принять во внимание все возможные способы решения. Во-вторых, надо взвесить альтернативные способы решения проблемы и выбрать тот, который является наилучшим, ответив на вопрос: «Можно ли с помощью данного способа достичь основной цели?» В-третьих, выбранный способ решения проблемы должно быть тщательно обдуман и только после этого реализован на практике. В-четвертых, необходима твердость в осуществлении принятого решения, несмотря на возможное сопротивление среды.

Заметим, что формирование готовности будущего учителя к приобщению школьников к ценностям физической культуры будет осуществляться эффективно в том случае, если студенты овладевают реальным опытом приобщения учащихся к ценностям физической культуры. Это становится возможным в период педагогической практики, поскольку ни моде- лирование педагогических ситуаций, ни решение педагогических задач не позволяют студентам реально организовать ценностно-ориентационную деятельность учащихся.

Одной из форм сочетания теории и практики является написание студентами курсовых работ по педагогике. Среди тем курсовых работ: «Методы ориентации школьников на здоровый образ жизни», «Физическое воспитание детей в условиях летнего оздоровительного лагеря», «Формирование ответственного отношения школьников к здоровью» и другие. Вне зависимости от выбранной темы курсовой работы преподаватель, осуществляющий научное руководство, нацеливает будущего учителя на необходимость обосновать, каким образом педагог приобщает школьников к ценностям в целом и к ценностям физической культуры в частности. Требованием к таким работам (в целях устранения реферативности изложения) является обоснование собственной точки зрения на рассматриваемую проблему с позиции физической культуры и ее ценностей.

Итак, формирование готовности студента - будущего учителя к приобщению учащихся к ценностям физической культуры в процессе изучения учебной дисциплины «Педагогика» осуществляется таким образом, что организация ценностно-ориентационной деятельности студентов обеспечивает формирование у будущих учителей опыта приобщения учащихся к ценностям физической культуры, а освоенные студентами ценности становятся ориентирами по воспитанию школьника, ответственно относящегося к собственному здоровью и здоровью окружающих людей, осознанно ведущего здоровый образ жизни.

\section{Список литературы:}

1. Минздрав: в России не осталось здоровых старшеклассников [Электронный ресурс] // Столетие: информационно-аналитическое издание фонда исторической перспективы. - http://stoletie.ru/lenta/ minzdrav_v_rossii_ne_ostalos_zdorovyh_starsheklassni kov_249.htm.

2. Коровин С.С., Малорошвило Л.Н. Ценности физической культуры: структура, характеристика // Самарский научный вестник. 2017. Т. 6, № 3 (20). C. 287-293.

3. Виленский М.Я. Образовательные ценности физической культуры в высшей школе: содержание, свойства, функции // Культура физическая и здоровье. 2017. № 1 (61). С. 62-67.

4. Востриков В.А. Ценности социума и физической культуры как феномены становления личности // реферативный журнал «Научное обозрение». 2016. № 2. С. 31-41.

5. Григорьева И.В., Волкова Е.Г. Современная система освоения ценностей физической культуры и ее инновационные направления // Воронежский научнотехнический вестник. 2015. Т. 4. № 1. С. 22-26.

6. Кораблева Е.Н. Структура, средства, система ценностей и функции физической культуры // Приоритетные научные направления: от теории к практике. 2016. № 27-1. С. 61-66.

7. Левченко Е.П. Содержание понятия «физическая культура // Проблемы и перспективы современного образования: сборник научных статей. Самара: ПГСГА, 2009. С. 117-131. 
8. Леготкина Л.Р., Лопатина А.Б. Физическая культура как система ценностей // Успехи современной науки. 2016. Т. 2, № 11. С. 46-48.

9. Лубышева Л.И. Концепция физкультурного воспитания: методология развития и технология реализации // Физическая культура. 1996. № 2. С. 11-17.

10. Лубышева Л.И. Современный ценностный потенциал физической культуры и спорта и пути его освоения обществом и личностью // Физическая культура. 1997. № 6. С. 10-15.

11. Пономарева Т.А. Интенционные ценности физической культуры студенческой молодежи // Педагогико-психологические и медико-биологические проблемы физической культуры и спорта. 2017. T. 12, № 1. С. 74-81.

12. Хрусталев Ю.М. От этики до биоэтики. Ростов-на-Дону: Феникс, 2010. 446 с.

13. Шустерман Р. Мыслить через тело: гуманитарное образование // Вопросы философии. 2006. № 6. С. 52-67.

14. Борисов А.Я. Готовность будущего учителя к приобщению школьников к ценностям физической культуры: методика формирования. Самара: ПГСГА, 2016. $108 \mathrm{c}$.

15. Левченко Е.П. Подготовка будущих учителей физической культуры к реализации здоровьесберегающих образовательных технологий. Самара: СГПУ, 2007. $188 \mathrm{c.}$

16. Смирнов Н.К. Здоровьесберегающие образовательные технологии и психология здоровья в школе. М.: АРКТИ, 2005. 320 c.

17. Мышление учителя: Личностные механизмы и понятийный аппарат / под ред. Ю.Н. Кулюткина, Г.С. Сухобской. М.: Педагогика, 1990. 104 с.

18. Туровский М.Б. Философские основания культурологии. М.: РОССПЭН, 1997. 440 с.

19. Кулюткин Ю.Н. Психологические особенности деятельности учителя // Мышление учителя. М.: Педагогика, 1990. С. 7-26.

20. Чарлтон Э. Основные принципы обучения здоровому образу жизни // Вопросы психологии. 1997. № 2. C. 3-13.

\section{DEVELOPMENT OF PROSPECTIVE TEACHERS' READINESS TO FAMILIARIZE SCHOOLCHILDREN WITH THE VALUES OF PHYSICAL CULTURE WHILE STUDYING «PEDAGOGY»}

(C) 2018

Borisov Alexandr Yakovlevich, candidate of pedagogical sciences, head of Physical Education Department Samara State University of Social Sciences and Education (Samara, Russian Federation)

Abstract. The paper considers the urgency of solving the problem connected with the development of prospective teachers' readiness to introduce schoolchildren to the values of physical culture in the context of preserving man as a social being and as a biological species. The values of physical culture are considered as a prerequisite for achieving a harmonious combination of bodily and spiritual principles in a person, as a condition for the full-fledged existence of a schoolboy, a student. Specific values of physical culture are singled out: «human motor activity», «human life», «health», «healthy lifestyle», «culture», «perseverance in achieving the goal», «moral perfection», «self-realization», etc. The author presents a structure of prospective teachers' readiness to familiarize schoolchildren with the values of physical culture, including cognitive motivational-value and activity components. Opportunities of «Pedagogy» for the development of prospective teachers' readiness to introduce students to the values of physical culture in theoreti$\mathrm{cal}$ and practical aspects are revealed. The theoretical aspect is the allocation of physical culture values at the scientific material level of «Pedagogy» sections (section «Introduction to pedagogical activity» - the values «human life», «culture», «persistence in achieving the goal», «self-determination», «self-organization» and others, section «Solving professional problems» - the values of «health», «healthy lifestyle», «perseverance in achieving the goal», «prestige of physical culture and sports», «freedom», «justice», etc.). The practical aspect is examples of development of prospective teachers' readiness to introduce schoolchildren to the values of physical culture during lecture and seminar classes in the sections «Solving professional problems» and «History of pedagogical thought in Russia and abroad». The conclusion is that the values mastered by the students will become the reference points for the education of the schoolchild who responsibly relate to their own health and the health of the surrounding people.

Keywords: readiness; student; future teacher; physical culture; value; value of physical culture; educational discipline; pedagogy; health; healthy way of life; pedagogical task; decision; reflection; orientation; initiation; schoolchild; formation; process.

\section{ТЕКСТУАЛЬНО-ДИАЛОГИЧЕСКИЙ ПОДХОД К ФОРМИРОВАНИЮ ГОТОВНОСТИ КУРСАНТОВ - БУДУЩИХ СОТРУДНИКОВ УГОЛОВНО-ИСПОЛНИТЕЛЬНОЙ СИСТЕМЫ К ГУМАНИСТИЧЕСКОМУ ВЗАИМОДЕЙСТВИЮ С ЧЕЛОВЕКОМ}

\section{(C) 2018}

Вдовин Сергей Александрович, кандидат педагогических наук, начальник юридического факультета Самарский юридический институт ФСИН России (2. Самара, Российская Федерация)

Аннотация. Статья посвящена проблеме подготовки будущего сотрудника уголовно-исполнительной системы, способного выстраивать отношения с окружающими людьми, в том числе и с людьми, преступившими закон и отбывающими наказание, на гуманистических основаниях. Актуальность гуманистического взаимодействия в условиях уголовно-исполнительной системы аргументируется с позиции идеи: «человек по своей природе, т.е. изначально, сущностно - добр». Предлагается определение гуманистического взаимодей- 